2015 Global Fashion Management Conference at Florence Proceedings: 799-800 (June 2015) http://dx.doi.org/10.15444/GFMC2015.05.06.03

\title{
THE GROWING CHALLENGE OF UNLEASHING THE POWER OF STRONG IDENTITIES VIA BRANDING AND BRAND COMMUNICATION - IS IT THE PRODUCT, THE DESIGNER, THE COMPANY, THE CITY OR COUNTRY BEHIND TO ACHIEVE AND SUSTAIN SUCCESS IN FASHION MARKETING?
}

\author{
Klaus-Peter Wiedmann, Leibniz University Hannover, Germany ${ }^{1)}$ \\ Carmen Rodriguez Santos, University of León, Spain \\ Gaetano Aiello, University of Florence, Italy \\ Raffaele Donvito, University of Florence, Italy \\ Bruno Godey, Rouen School of Management, France \\ Daniele Pederzoli, Rouen School of Management, France
}

\begin{abstract}
Fashion brands are influenced by multiple identities. Even though, for example, the brand name might still be associated with one or more creative founders (Gucci, Prada, Chanel, Hermès, Adidas, Joop) the brand image, and moreover the overall brand reputation are influenced by many different identities. For instance, a specific product identity (e.g., Gucci's Bamboo Bag), the identity of the city or country of origin (Florence, Italy), the identities of well-known key customers as brand ambassadors (Sophia Loren, Vanessa Redgrave, Lady Diana, Naomi Watts etc.). Of course, also fashion brands who are not directly associated with the name of creative founders are composed of the effects of several identities. In the case of e.g. Nike especially successful athletes (Steve Prefontaine, Michael Jordan etc.), specific sports and sport events, and product lines tailor-made for them did help to build a strong brand reputation. All in all, it seems to be expedient to understand fashion brands as more of less complex systems composed of several identities. To deal in more detail with such "brand systems" is becoming particularly important against the background of several strategic challenges - e.g., when fashion brands are growing older and the creative founders lose their specific gravitational power, when in the process of internationalization new countries gain more and more importance who's citizens might not have a strong access to the existing brand reputation drivers, or simply when in the context of the growing global competition the fashion brand needs to be "refreshed".
\end{abstract}

Against the background of cultural differences, or even - as within countries - lifestyle differences between different groups of customers, it can also be quite possibly that very different reputation drivers account for the success of a brand. Thus, it is necessary to identify, in different contexts, the relevant reputation drivers, and to analyze which interplay of those drivers might be particularly promising. Is it the creative founder, the corporate heritage, the country and/or city of origin, a special designer, a specific corporate culture, an outstanding product design, attractive key customers etc.? Which combination of such identity factors leads to what kind of success (e.g., brand loyalty, brand trust, price premium)? Will, for instance, heritage especially lead to brand trust, whereas an outstanding product design and specifically

\footnotetext{
1)wiedmann@m2.uni-hannover.de
} 
attractive key customers create the readiness for a higher price premium? And, is it necessary to create sub-brands to especially highlight specific identities in the process of building a brand system (e.g., the sub-branding of a Michael Jordan product line in the case of Nike)? Or is sufficient to only communicate an alignment with the brand (e.g., ads showing Naomi Watts wearing a Gucci Bamboo Handbag)? In other words, which kind of brand system, and which kind of brand communications has to be designed to attract specific target groups and to sustain competitive advantages?

The present contribution aims to present a conceptual framework for analyzing "brand systems" in the fashion industry. Concomitantly, an approach of measuring such brand systems will be presented. Furthermore, a concept for analyzing the impact of several sub-identities on the development of the overall brand reputation and brand success against the background of existing contingencies will be outlined. With the introduction and discussion of such a conceptual framework it especially is intended to initiate the launching of an international research project which attempts to find an answer basically to the following question: Which via an integrated branding and brand systems communication carefully crafted composition of sub-identities might be how successful under what kind of situational conditions?

Keywords: brand systems in fashion industry, brand identities and reputation, measuring the interplay of multiple identities, adapting fashion brands to specific contingencies, cultural and lifestyle differences, success drivers of brand systems, international research project

\section{Basic Framework:}

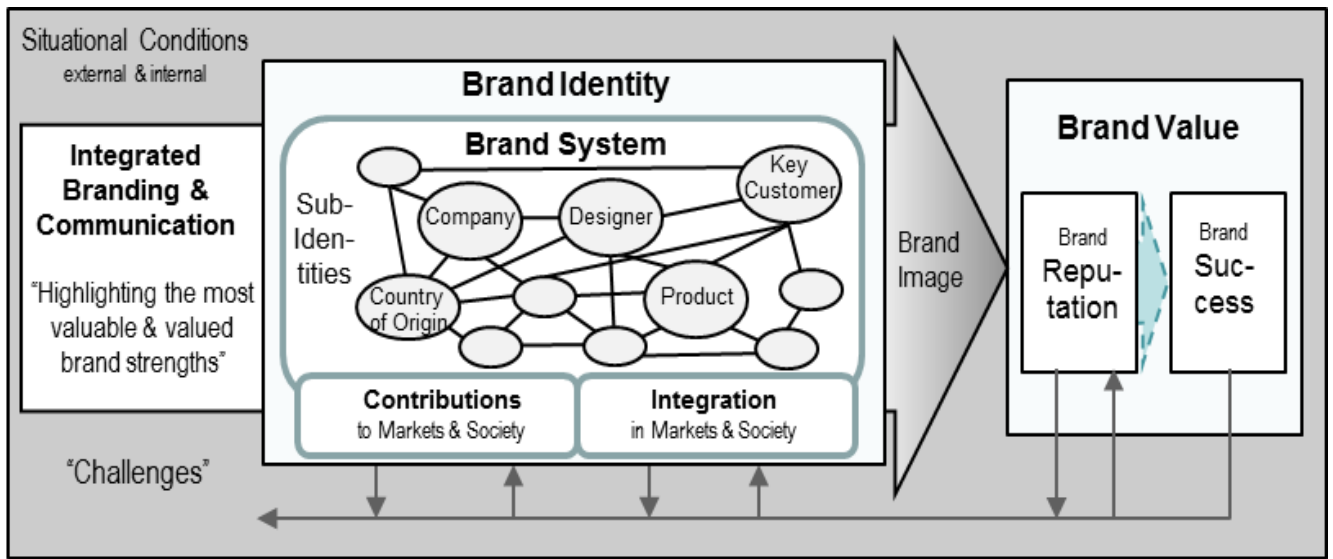

